\title{
UMA HISTÓRIA DE DUAS CIDADES: TRAJETÓRIA E VIDA DE ABDON BAPTISTA ${ }^{1}$
}

\author{
Marco Aurélio Barbosa ${ }^{2}$
}

- Enviado em 26/01/2016

- Aprovado em 15/02/2016

\begin{abstract}
RESUMO
Este trabalho pretende tratar da trajetória de vida de Abdon Baptista, que foi Médico, Jornalista e Político, nascido na Bahia no ano de 1852, tornando-se figura notória em Joinville, Santa Catarina. Sua trajetória é complexa e reúne um conjunto exuberante de estratagemas, que levaram à sua ascensão política e social, de descendente de ex-escravos a Prefeito de Joinville, Senador e Vice-Governador de Santa Catarina em 1905. Ao reconstituir a trajetória para ascensão desta figura notável, vê-se como ele se reinventa, acumula capitais sociais ao tornar-se médico, se afirma em meio à nova fronteira do Norte Catarinense, adentra a teia de relações de poder deste universo, através da inserção em uma família da tradicional oligarquia local e mesmo funda-se como importante personalidade no momento de transição em que se afiguram diversos eventos importantes para o Brasil e o mundo, entre os anos de 1880 até 1922 , data de seu falecimento.
\end{abstract}

Palavras-chave: Abdon Baptista. Redes de Sociabilidade. Negro. Trajetória de Vida. Política e Poder

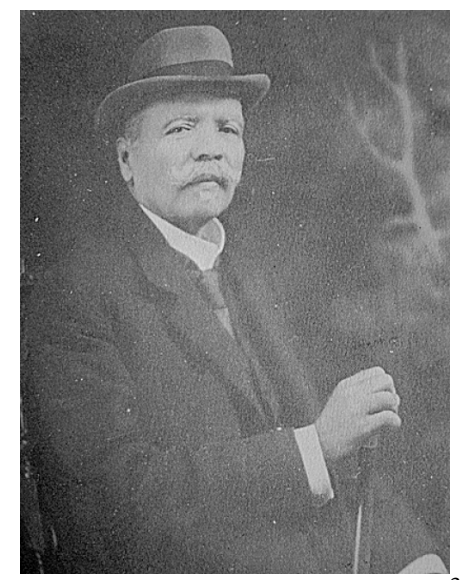

ABDON BAPTISTA (1851-1922)

1 Monografia defendida no DECISO-UFPR como requisito para a conclusão do bacharelado em Ciências Sociais em 2014.

2 Graduado em Sociologia pela Universidade Federal do Paraná (UFPR); Licenciado em História pelas Faculdades Integradas "Espírita" (UNIBEM); Especialista em Relações Étnico-raciais pelo Núcleo de Estudos AfroBrasileiro da Universidade Federal do Paraná (NEAB-UFPR); Mestrando em Sociologia pela Universidade Federal do Paraná (UFPR). Endereço eletrônico: barbosa.marco@gmail.com 


\section{INTRODUÇÃO}

Este artigo visa trabalhar a questão do negro e sua invisibilidade social, isto é, o ocultamento de sua participação na construção da sociedade brasileira tendo como fio condutor a trajetória de vida de Abdon Baptista. Ao reconstituir a trajetória desta personagem, vê-se como ela se reinventa, acumula capital social ao tornar-se médico, se afirma em meio a nova fronteira do Norte Catarinense, adentra a teia de relações de poder através da inserção em uma família da tradicional oligarquia local e mesmo torna-se uma importante personalidade no momento de transição em que se afiguram diversos eventos importantes para o Brasil, entre os anos de 1880 até 1922, data de seu falecimento.

A História que envolve a vida de Abdon é bastante curiosa. De fato, como pode um homem negro, em pleno século XIX, sobrepor-se a imagem de descendente de ex-escravos, tornar-se médico, casar-se dentro de uma das famílias oligárquicas mais importantes de Santa Catarina e ainda, alçar-se aos mais importantes cargos políticos em Joinville, no Estado de Santa Catarina, um Estado reconhecidamente dito como branco, germânico e europeu? Teria o fato de ser negro influído em sua trajetória? Como se sobressaiu um "negro no mundo dos brancos"? Quais as estratégias e mecanismos utilizados por este para atingir o status em uma sociedade escravocrata e mesmo manter-se nesta e apesar desta? Por que a imagem de Abdon não aparece associada à sua identidade negra e como se é possível pensar que esta questão pode ter sido ocultada?

Ao observar a História oficial do Brasil, o elemento negro na conjugação e construção de sua identidade, desaparece como elemento constitutivo desta. Desaparecimento este firmado na ideia de europeização, ou mesmo das narrativas que se formam acerca dos indivíduos, onde a participação do negro fora nula ou quase incipiente. Afirmação amplamente refutada, nas obras de Octavio Ianni (As Metamorfoses do Escravo) e Fernando Henrique Cardoso (Capitalismo e Escravidão no Brasil Meridional) e entre outras publicações, que pode apontar para um possível ocultamento de determinados vestígios e/ou elementos discrepantes aos quais podem remeter a ideia de construção da invisibilidade do negro nesta sociedade.

Para Leite (1996, p.41):

(..)a invisibilidade do negro é um dos suportes da ideologia do branqueamento, podendo ser identificada em diferentes tipos de práticas e representações. A noção de invisibilidade, utilizada por vários autores para caracterizar a situação do negro, foi utilizada pela primeira

3 Fonte: http://ndonline.com.br/joinville/colunas/memoria/229604-politica-em-portugues-bem-claro.html. Acesso 06.fev.2016. 
vez na literatura ficcional americana por Ellison (1990) para descrever o mecanismo de manifestação do racismo nos Estados Unidos, sobretudo na entrada dos ex-escravos e seus descentes no mercado de trabalho assalariado e as relações sociais decorrentes de sua nova condição de status. Ellison procura demonstrar que o mecanismo da invisibilidade se processa pela produção de um certo olhar que nega sua existência como forma de resolver a impossibilidade de bani-lo totalmente da sociedade.

Ou seja, não é que o negro não seja visto, mas sim que ele é visto como não existente. É interessante notar que este mecanismo, posteriormente percebido também no Brasil, ocorre em diferentes regiões e contextos, revelando-se como uma das principais formas do racismo se manifestar, como um dispositivo de negação do outro. A invisibilidade pode ocorrer no âmbito individual, coletivo, nas ações institucionais e nos textos científicos.

\title{
2. TRAJETÓRIA DE VIDA COMO MÉTODO DE ANÁLISE SOCIOLÓGICA
}

Trabalhar com a trajetória de vida, oferece uma condição que guarda em si elementos de alto grau de complexidade, já que ao se optar pela análise e/ou reconstrução, da biografia de um sujeito, várias nuances se acham presentes. Contudo, pensar a realidade social tendo como ponto de partida a trajetória de vida, torna necessário uma pequena definição e/ou delimitação do tema em questão, assim, de acordo com Mocelin $(2010)^{4}$ :

\begin{abstract}
A história de vida é uma narração biográfica de acontecimentos que um ator social realiza para justificar suas ações e condições presentes. Em narrativas desse tipo, os atores expõem apenas o que eles consideram relevante destacar. Não existe uma cronologia linear, mas um encadeamento de fatos marcantes, feito através de um processo de seleção de eventos a qual o indivíduo atribui sentido, justificados entre si através de relações inteligíveis.
\end{abstract}

Bourdieu (2006) vai transpor o conceito de história de vida introduzindo o conceito de trajetória de vida, que está articulado aos conceitos de campo e de habitus. Na sua concepção, a trajetória de vida é linear, cronologicamente ordenada por eventos sucessivos, ou seja, em posições que foram sucessivamente ocupadas pelo agente num campo. Por consequência, a narrativa do agente será relacionalmente determinada dentro do campo, e sustentada em sua história passada, acumulada, espécie de "script", que orienta o perfil e a ação posterior da trajetória do indivíduo, ou seja, seu habitus. Este tipo de análise tem como elemento recursivo, um enfoque histórico, desde

4 História e trajetória de vida: Fato Sociológico blog (internet). Porto Alegre,RS. jun. 2010. Disponível em: <http://fatosociologico.blogspot.com.br/2010/07/historia-e-trajetoria-de-vida.html>. Acesso em: 05 mar. 2014. 
modo, surge a necessidade de que o trabalhado seja realizado levando em conta as fontes históricas, embora se trate de um estudo de cunho sociológico.

Como pensar a trajetória de vida de um homem? Por onde começar? São inquietações que surgem ao se tratar de uma figura histórica como Abdon Baptista. Bourdieu (2006, p.183) aponta que a história de vida trata-se de um conjunto de eventos sucessivos que dizem respeito a «existência individual concebida como uma história e o relato desta vida», onde observa que isto «é exatamente o que diz o senso comum, isto é, a linguagem, que descreve a vida como um caminho», ou seja, trajetória.

Deste modo, embora guarde uma certa redundância, trajetória refere-se ao trajeto - uma linha mais ou menos fixa - percorrida pelo sujeito onde se acha delineado de antemão um início, etapas e um fim, no duplo sentido, de término e de finalidade, que é transmitida pelo sujeito. Neste caso ao pensar a trajetória no que toca o discurso oficial, Abdon não é representado ou apresentado como um homem negro e/ou de descendência africana o que pode apontar para o processo de invisibilização.

O primeiro documento de Abdon analisado é a sua tese de conclusão do curso de Medicina defendida no ano de $1874^{5}$, no qual faz vários agradecimentos sem, no entanto, citar os nomes dos pais e irmão. Agradece em especial a memória de seu "Mano Joaquim", iniciando um conjunto de dedicatórias a um grande número de pessoas, as quais foram cuidadosamente nomeadas e classificadas segundo seus afazeres, Doutor, Tenente-coronel, etc. A tese, intitulada "Vantagens e desvantagens dos processos de amputação em relação ao curativo e accidentes consecutivos" trata acerca dos processos de amputação, assepsia e tratamento desse procedimento. $\mathrm{O}$ trabalho conta também com as partes de "Sessão Médica" onde trata do tema " A civilização desenvolve ou refreia a prostituição?" e a "Sessão Assessória" com o tema "Pode-se considerar herdeiro legítimo o filho de uma viúva nascido 10 meses depois da morte do pai?" e que acabam por se tratar de um conjunto de aforismos, que a princípio não tem grande relevância.

Retrocedendo um pouco mais, em 1869, ano provável de seu ingresso no curso, vê-se que este assina com o nome de Abdon Senen Baptista, o que parece um detalhe sem muito significado, contudo evidencia-se o aparecimento ou desaparecimento do sobrenome Senen. O que o levou a

5 BAPTISTA, Abdon (1874). Vantagens e desvantagens dos processos de amputação em relação ao curativo e accidentes consecutivos. Salvador, BA. U.S .National Library of Medicine Disponível em:< http://collections.nlm.nih.gov/ext/kirtasbse/101472120/PDF/101472120.pdf > Acesso em: 10/01/2016 
suprimir o segundo nome? Esta súbita, "interdição" fez com que o Sr. Alberto ${ }^{6}$, que também teve acesso aos documentos, a refletir e pesquisar junto as igrejas de Salvador a certidão de nascimento de Abdon. Abdon Baptista, teria nascido Abdão Senen, filho de Thereza Maria de Jesus, em Vera Cruz de Itaparica, com a diferença de um ano entre o registro oficial em 1851 e o criado nos tempos da Faculdade, que apontam para 1852 conforme apontou o Sr. Alberto e o documento de matrícula de Abdon no curso de Medicina e as fontes oficiais e algumas literaturas que apontam para o ano de 1852. Tratar-se-ia Abdon do mesmo Abdão? Que elementos teriam feito ou provocado esta mudança de nome? Sobre qual pretexto? Seria a trajetória de Abdon uma invenção do próprio Abdon?

Assim, ao observar ainda que de modo superficial, um primeiro momento não retratado da trajetória de Abdon, percebe-se que a primeira fase da vida deste importante político catarinense de origem baiana é bem diversa, ou pelo menos oferece um novo gradiente a vida deste. Por outro lado, apresenta ainda uma nova personagem Thereza Maria de Jesus ${ }^{7}$, ao que tudo indica mãe solteira; e um novo cenário a Ilha de Vera Cruz de Itaparica.

Ao iniciar este debate a respeito da Freguesia de Vera Cruz é importante salientar que esta, compreende uma região dentro da Ilha de Itaparica, hoje região que compõe o município de Salvador, da qual conseguiu-se chegar a um panorama geral do lugar na época por intermédio do pesquisador Wellington Castellucci Junior que desenvolveu alguns trabalhos e artigos, assim como uma obra, que traz informações com relação a vida e organização social das pessoas e do seu contexto neste local durante o século XIX.

Castellucci (2005a, p.1) busca tratar acerca do panorama social e demográfico de Vera Cruz, no qual inicia com o interessante subtítulo «Uma população mestiça», no qual faz um inventário do quadro populacional da ilha cruzando dados referente aos falecimentos, registros policiais da época e mesmo séries estatísticas dos sensos de então, com objetivo de elaborar um olhar mais preciso à respeito da composição étnica da população local. A argumentação realizada pelo autor aponta Vera

\footnotetext{
${ }^{6}$ Alberto Durão Coelho, é o bisneto mais velho do segundo casamento do médico baiano, que contribuiu para a pesquisa com importante base de dados (documentos e registros), sendo dela também informante, acrescendo depoimentos e informações relevantes à respeito de Abdon Baptista.

${ }^{7}$ A busca sobre informações à respeito de Thereza Maria de Jesus, mostrou-se infrutífera, na medida em que não foi possível apurar nada a seu respeito, a não ser registro lavrado no livro de registros de batismos que traz em sua capa "Baptismo da Freguesia de Vera Cruz 1851-1884, deste modo, a primeira estratégia tem haver como um levantamento em relação ao possível local de nascimento de Abdon.
} 
Cruz como um local de população de maioria não branca, ou seja, negra e parda, elemento que destoa se comparado a população da capital do Estado da Bahia à época com $30 \%$ da população branca, o que em muitos aspectos aponta para uma prevalência da população não branca, como um fato.

Outro aspecto a ressaltar é que boa parte desta população não branca foi atraída pela possibilidade de uma forma de trabalho mais amena, bem como a valorização e a necessidade de mão de obra, um atrativo para estes elementos que buscavam fixar-se no local, como salienta Castellucci Junior (2005a, p. 3) a dizer que:

(...) foi a ausência da grande plantation que atraiu uma quantidade significativa de homens e mulheres libertos para se acomodarem em Itaparica. Como alternativa ao desgastante trabalho do eito, os libertos buscavam se acomodar nas áreas litorâneas, onde pudessem viver de forma menos penosa e extrair, mais facilmente da natureza, os alimentos para a sua subsistência.

A forma de trabalho e mesmo a organização da ocupação da ilha se dava de forma diferente do que ocorria no continente onde o trabalho ocorria em grandes propriedades e utilizava-se a mão de obra escrava de modo extensivo, já que se tratavam de pequenas propriedades e os proprietários de escravo se encontravam empobrecidos ou não contavam com os recursos necessários à manutenção e tratamento de grandes contingentes de cativos, fazendo com que estes tenham que produzir formas diferenciadas de organização do trabalho.

Esta organização de trabalho é aliada a um processo bastante contraditório, que tem a ver com o afluxo de mão de obra que estava ocorrendo pelos anos 50 do século XIX neste local, conforme aponta Castellucci Junior (2010b, p.):

(...)entre os anos 1850-1888, a configuração da escravaria da Ilha modificou rapidamente. Mesmo antes do fim do tráfico, naquela área não havia uma grande discrepância numérica de escravos homens sobre mulheres, situação que diferia das áreas de grande plantation. Mas, na virada da década de cinquenta para a seguinte, os senhores viram seus escravizados falecerem e não tiveram condições de repor seus estoques, entre outras razões, por conta da decadência de uma das principais atividades econômicas: a caça de baleia. Por isso, muitos senhores se desfizeram de parte dos seus subalternos do sexo masculino, priorizando mulheres e crianças para o exercício de tarefas consideradas menos penosas. Também passaram a comprá-las em áreas do Recôncavo ou mesmo de outras províncias.

Este fato possibilitará que muitos escravos e ex-escravos, negociar a compra de sua liberdade e mesmo acesso a frações das pequenas propriedades e algum tipo de pecúlio deixado pelos seus antigos senhores, como forma de manter a pouca mão de obra existente. Por outro lado, 
as novas sociabilidades darão margem a relações mais profundas entre senhores, escravos e novos egressos nestes espaço, onde Castellucci Junior (2010b, p.71) aponta que:

(...) Muitas vezes, solteiros, estrangeiros e sem família, ao testarem nem sempre declaravam explicitamente tais relações, mas reconheciam subliminarmente suas dívidas para com aquelas mulheres. No íntimo, elas não só levaram uma vida amorosa com aqueles sujeitos, como cuidaram diariamente deles, principalmente dos mais idosos, sem condições de morarem sozinhos.

Quando cativas, muitas receberam a liberdade e a pequena herança de seus companheiros, numa clara revelação de que a condição de escrava não impediu a transmissão da herança e a construção de laços de afetividade entre sujeitos que se encontravam em lados opostos do regime escravista. Ao morrerem, alguns senhores deixavam os bens para as suas agregadas ou cativas, sem entrar no mérito das suas ligações com elas, fazendo sutil menção aos seus "bons serviços" prestados. Foi o que declarou o comerciante espanhol Pedro Maria de Souza, em 1870, dono de uma casa de molhados na Gamboa: "Declaro que tenho em minha casa a dona Maria das Neves dos Santos a quem instituo por minha herdeira dos remanescentes, e isto faço em virtude dos bons serviços que me tem prestado."

Este fato evidencia não só a formação de novas sociabilidades, mas uma nova composição familiar, isto é, uma família mestiça, no qual os não brancos se associam para a formação de novas unidades familiares, ainda, que não explicitamente assumidas. Gilberto Freyre (1981, p. 442- 443) aponta esta relação como objeto de um certo liberalismo patriarcal:

(...)liberalidade esta entendida no sentido de certa frouxidão moral, promovendo o livre intercurso sexual de brancos dos melhores estoques - inclusive eclesiásticos, sem dúvida nenhuma, dos elementos mais seletos e eugênicos na formação brasileira - com escravas negras e mulatas (...). Resultou daí grossa multidão de filhos ilegítimos - mulatinhos criados muitas vezes com a prole legítima, dentro do liberal patriarcalismo das casasgrandes; outros à sombra dos engenhos de frades; ou então nas 'rodas' e orfanatos.

Este ponto torna-se importante pois joga certa luz na história familiar de Abdon Baptista, na medida em este tem sua origem familiar e social neste mesmo local. Assim o fato de Abdon, não ter em seu registro de nascimento a filiação paterna poderia ter origem nas relações acima apontadas o que levou a mudança de nome promovida pelo próprio Abdon. Vale aqui relembrar o que aponta Bourdieu, ao tratar da questão nome, do que Bourdieu (2006, p.187), chama atenção

(...)para o nome próprio é o atestado visível da identidade do seu portador através dos tempos e dos espaços sociais, o fundamento da unidade de suas sucessivas manifestações e da possibilidade socialmente reconhecida de totalizar essas manifestações em registros oficiais, curriculum vitae, cursus honorum, ficha judicial, necrologia ou biografia, que constituem a vida na totalidade finita, pelo veredicto dado sobre um balanço provisório ou definitivo. "Designador rígido", o nome próprio é a forma por excelência da imposição arbitrária que operam os ritos de instituição: a nominação e a classificação introduzem 
divisões nítidas, absolutas, indiferentes às particularidades circunstanciais e aos acidentes individuais, no fluxo das realidades biológicas e sociais.

Ou seja, um nome pode designar e ou revelar o status social de um sujeito, para o bem ou para o mal deste, e neste caso em uma sociedade em que o negro e seus descendentes, mesmo os mulatos claros, eram mal vistos, "disfarçar" a sua identidade era disfarçar um estigma desonroso. Estigma aqui no sentido empregado por Goffman (1988), no qual este faz uma reflexão a respeito do que seja o estigma tendo por base em um primeiro momento a classificação de estigma como uma espécie de marca e ou identificação que determinavam o status moral e social, em geral desonroso dos sujeitos que as possuíam. Assim, o estigma estava ligado, grosso modo, às "deficiências físicas", morais e sociais, das quais o indivíduo é portador, de modo tal que revelá-las, a tornaria um sujeito desacreditado, perante aqueles tidos como normais, isto é, um indivíduo inferior a quem certas expectativas desejáveis e esperadas não podem ser realizadas. Sendo que a realização ou não destas expectativas e a revelação deste status inferior, como no caso de Abdon, provavelmente filho de uma mulher negra e homem branco e, portanto, um mestiço, ainda que 'claro' o que demonstraria este status, em uma sociedade onde o não branco ocupava um lugar inferior. Fato que teria levado Abdon a mudança de nome e filiação, de origem e data de nascimento, no intento, de melhor ocultar esse status indesejado.

Deste modo, poderia pensar-se a trajetória de Abdon com sua entrada no curso de medicina, como uma forma de romper uma fronteira social estabelecida para os indivíduos com suas características, fato este que terá grandes desdobramentos em sua vida, na medida em que este estará com certo efeito em uma "região fronteiriça" do ponto de vista social, o que o obrigará necessariamente a construção de uma vida negociada, no qual esta se fará sentir em maior ou menor grau dependendo da estrutura e contextos nos quais estiver inserido.

Pensar a entrada de Abdon no campo da medicina do século XIX é, em muitos aspectos para o bem e para o mal, pensar o significado do que era ser médico naquele contexto, tendo em vista o seu valor simbólico, afastando sob muitos sentidos a noção romântica do "anjo de branco", prénoção esta desconstruída e "esmiuçada", no artigo de Coradini (1997) intitulado "Grandes Famílias e Elite 'Profissional' na Medicina no Brasil", na qual em linhas bastante gerais, expõe a entrada e a participação na área da medicina como um projeto de legitimação, ascensão e acesso ao poder, bem engendrado e acabado, no qual o diploma e um certo "saber" ligado a um "capital cultural institucionalizado" aparecem como peça chave no que toca este projeto de poder. 
Salientamos aqui a importância do diploma escolar no jogo de relações sociais onde este desempenha um importante meio para o recrutamento, reprodução e a renovação destas elites. Torna-se clara a necessidade da aquisição destes títulos pelos sujeitos, uma vez, que este garante um certo tipo de capital social que lhe dá legitimidade dentro da estrutura social de poder, e porque não dizer, posicionando-os/reposicionando-os e afirmando-o/reafirmando-os nesta estrutura frente aos outros atores sociais, pelo acúmulo de capitais decorrentes deste processo, do qual o capital social junto do cultural formam um conjunto bastante interessante.

Trata-se aqui de forjar os elementos necessários ao surgimento, manutenção e reprodução desta elite, tanto no que diz respeito às suas relações sociais, capitais culturais e que culminam neste caso em particular com a entrada no curso de medicina que não se dá ao acaso, isto é, tendem a ser resultado de uma estratégia - na maioria dos casos - bem definida, no intuito de reforçar os capitais existentes e mesmo ampliá-los. Assim, a entrada no curso de medicina, não se tratava apenas de um processo de educação para a mundo trabalho, que teria por premissa formar um profissional dotado das competências e habilidades próprias da função, mas, antes seriam um primeiro passo do indivíduo dentro de um conjunto de relações de poder ou ainda, o ápice ou coroação de um processo de consagração destes sujeitos.

Isto é, está fundada em uma base relacional de reconhecimento e de consagração, que em certos aspectos se dá por conta de um certo acúmulo de capitais sociais, produzidos e/ou herdados, que nesta lógica, é o elemento responsável por produzir a mediação e equivalência dos diferentes capitais, que asseguram a existência desta elite e sua reprodução.

Ou seja, o diploma em certa medida equivale às outras formas de capital, como o capital sonante, isto é, ao dinheiro sob diversos aspectos, de modo tal que o acesso a algum deles poderia em certa medida equivaler ao acesso as outras formas de capital, consistindo assim em um bom requisito para no que toca ascensão social de alguns sujeitos dentro desta estrutura por exemplo.

Assim, poderia presumir-se que a entrada de Abdon neste campo, poderia estar ligada a um certo projeto de "empoderamento" individual por assim dizer, e mesmo à entrada em um círculo de relações privilegiadas capazes de alçá-lo socialmente a outras dimensões sociais. Ou seja, o título é apontado como um importante elemento de ascensão social na medida em que se presta como elemento de distinção social, bem como de socialização entre os grupos portadores destes, na medida em que suscita laços de sociabilidade e reciprocidade entre estes (CORADINI, 1997). 
Isto, em parte ocorre pela inexistência de campos efetivos- completamente definidos e com limites claros - fato este que permitia a estes indivíduos a penetração nas mais diferentes esferas da sociedade, inclusive capacitando-o para a vida política. Fato decorrente do campo da medicina ser naquele contexto, composto por um grande conjunto de heterônomas, na medida em que não existiam aí, disposições completamente fixadas e que limitasse a ação e a competência dos sujeitos.

Nessa perspectiva as relações de poder e cientificidade da academia de medicina misturavase a questões políticas pelo caráter pré-científico do campo e pelas relações de cordialidade apontadas como aquelas por Sérgio Buarque de Holanda ${ }^{8}$, que se achavam imiscuídas nas relações, onde às disputas do mundo científico misturavam-se a questões políticas, de personalidade e mesmo pessoais. Este caráter político se fazia presente na disputa de concepção científica dentro do campo acadêmico e tinha sob muitos aspectos esta lógica que se fazia presente neste embate no que observa-se inclusive a "perseguição" política, de tal modo que obrigava mesmo os agentes neste presente, a dele se ausentarem.

Contudo, amiúde estes fatos acabam por ter importante contribuição na formação desta elite "profissional" no que diz respeito a formação de um ethos político que vai construindo e sedimentando-se ao lado da formação técnico-científica dos mesmos.

Outro ponto importante a salientar é que no, entanto, havia uma certa diferenciação entre os médicos na medida em que haviam aqueles que viviam do clinicar, os que se dividiam entre a carreira política e a médica e carreira política e acadêmica.

Entretanto, no caso de Abdon durante a sua formação acadêmica este jogo de relações não está tão claro, deixa-se apenas entrever, no seu ato de matrícula ocorrido no ano de 1869, onde paga "à vista" o valor de um ano de faculdade, elemento que aponta ou pelo menos indica um padrinho de posses, disposto a investir em sua carreira introduzindo-o no curso de Medicina e deste modo nesta rede privilegiada de relações. Por outro lado, o próprio curso por si só se torna ocasião privilegiada para a construção, manutenção e ampliação das redes sociais, mesmo de cumulação de capitais sociais pelos indivíduos.

Por outro lado, Coradini (1997) evidência a importância da construção de determinadas redes sociais estabelecidas dentro do campo, que são também promotoras e guardiãs de determinadas memórias capazes, de criar vínculos entre os sujeitos, afirmar e fortalecer estas

\footnotetext{
${ }^{8}$ BUARQUE, Sérgio (1994). Raízes do Brasil. RJ: José Olympio.
} 
relações, em suma, revigorar e dar estofo, bem como consagração a determinados atores dentro (inclusive) de um imaginário em relação ao médico.

Do que a genealogia ocupa um lugar capital no que diz respeito a pesquisa do campo da medicina e seus desdobramentos visto que ela aponta para um conjunto de capitais herdados pelos sujeitos que contam como forma de consagração e mesmo de afirmação da autoridade de determinados sujeitos, resultantes daquilo que pode enquadrar-se naquilo que Weber (2002) compreende como uma forma de dominação tradicional.

Olhando para este quadro, onde as trajetórias familiares dentro deste campo que se enuncia de forma tão fremente, não são de se estranhar a necessidade de Abdon de conjurar Hermenegildo José Baptista ${ }^{9}$, adotando seu sobrenome, ou mesmo tomando-o para si. Do que se pode supor que seu nome, bem como a trajetória familiar a que este reclamava para si, deveria de algum modo suscitar uma imagem mais imponente do que os nomes de santo que até então ostentava, Abdon e Senem. ${ }^{10}$

Contudo, mesmo para o sujeito consagrado ou aquele que pretende construir sua própria biografia, parece interessante notar a circulação destes indivíduos em busca de locais onde pudessem se desenvolver ou que permitissem seu crescimento, ao invés de permanecerem em lugares centrais, de tal forma que adquiriam um certo grau de centralidade ao migrarem para a regiões ditas mais periféricas, onde Coradini (1997, p.450) se utiliza do exemplo de Nava, em que aponta que, "era o processo do médico se fixar no interior. Apadrinhado por um fazendeiro que lhe dava o partido de sua fazenda e da dos amigos da redondeza. Dessa forma já se chegava com clínica feita e área de atividade demarcada. Era só esperar o dinheiro." No entanto, a aliança matrimonial pôs em confronto estilos de vida: descendente "de uma família citadina, filho de um comerciante liberal, meu pai assim que conheceu melhor a sogra rural, escravocrata, dominadora e violenta,

\footnotetext{
${ }^{9}$ Provável pai de Abdon Baptista, levando-se em conta o fato de não haver encontrado registro oficial que evidencie de forma concreta a filiação de deste à Hermenegildo, já que a fonte documental mais antiga, isto é, seu assento de batismo (espécie de registro de nascimento fornecido pela Igreja Católica da época) não continha o nome do pai, apenas da mãe e padrinhos, vindo o nome de Hermenegildo e sua esposa, a constarem somente na tese de conclusão de curso de Abdon. No entanto, Hermenegildo conforme apontam registros do Almanak Administrativo Mercantil, e Industrial da Bahia - 1854 a 1870 , era residente na Ilha de Vera Cruz de Itaparica , na Ladeira da Ordem Terceira de São Francisco, tendo exercido diversos cargos públicos como de Procurador do Foro, Tenente e Capitão da Guarda Nacional.
}

${ }^{10}$ Santos Abdon e Sennen (? - C. 254 ), em vários calendários e martirologias antigos os santos Abdo, Abdus, e Senna, Senna Zenn são reconhecidos pela Igreja Católica Romana, e sua festa é celebrada em 30 de julho. Em algumas localidades celebra se no 20 de março ou no primeiro domingo de Maio. Fonte: Wikipédia, Abdó i Senén.Disponível em: http://ca.wikipedia.org/wiki/Abdó_i_Senén. Acesso em: 28/11/14. 
tomou-lhe horror" Coradini (1997, p.450). Assim, pelas relações se poderia chegar a um bom casamento e mesmo a entrada em uma rede de poder bem estruturada que permitisse um certo grau de ascensão social por meio do apadrinhamento e mesmo o cunhadismo ou genrocrácia.

Ao observar-se esta relação vê-se uma grande similaridade com o que ocorre em relação a trajetória de Abdon, que em 1880 pede exoneração do cargo de Promotor Público na Bahia, retirando-se para São Francisco do Sul/SC, onde vai exercer seu ofício de médico, trava relações com o Coronel José Antônio d'Oliveira para posteriormente casar-se com sua filha, se introduzindo em uma estrutura de elite, bastante proeminente na região deste Estado.

\title{
3. ABDON: DA BAHIA À SANTA CATARINA
}

Mafra, Cardoso \& Hoff $(2007,116)$ apontam que:

\begin{abstract}
Abdon Batista nasceu em 1851, em Salvador, e formou-se médico, vindo a radicar-se em São Francisco do Sul, em 1870; depois, em Joinville, onde desempenhou quase todos os cargos públicos. Na virada do século XIX para o XX, foi o principal político da cidade e muito respeitado em todo o estado por assumir a liderança do Conselho dos Intendentes. Foi prefeito do município de 1915 a 1921, ano em que faleceu. Associou-se às empresas, primeiro de Oscar Schneider, prefeito de 1907; depois, criou a empresa A Baptista \& Cia., de erva- mate. Elegeu-se sucessivamente para vários cargos, atuando, então, por intermédio do Partido Republicano Catarinense. De 1880 a 1922, exerceu de fato o papel de "coronel" da política, adversário de Hercílio Luz.
\end{abstract}

Entretanto, uma pesquisa nos periódicos nacionais do acervo da Hemeroteca Digital Brasileira, associadas a documentos gentilmente cedidos pelo Museu de Medicina de Salvador, bem como, documentos cedidos pela família, apontam algumas inconsistências na descrição dos autores acima mencionados, no que toca a chegada de Abdon à Santa Catarina. Segue uma pequena cronologia de Abdon baseada na documentação analisada:

- Entre os anos de 1867 e 1869 Abdon realizava os testes para o seu ingresso e matrícula na Faculdade de Medicina de Salvador;

- Julho de 1873, ele escreveu um artigo para um jornal acadêmico da Faculdade de Medicina de Salvador, tratando acerca dos prognósticos por ele observado durante a visita ocorrida a um doente em abril daquele mesmo ano;

- Em 1874, cursava o $6^{\circ}$ ano do curso de medicina, período em que assume o cargo de Vacinador Público; 
- Em 08 de Setembro de 1877, o Jornal "O Monitor" (Salvador/Bahia) apresenta um requerimento a respeito do pagamento de seu salário de Vacinador Público, que parece estar em atraso na ocasião;

- Em 06 de outubro de 1878, o Jornal "O Monitor" (Salvador/Bahia) torna a solicitar, via mídia impressa o requerimento que diz respeito ao pagamento de seu salário de Vacinador Público;

- Em 19 de Setembro de 1879, o Jornal “O Monitor” (Salvador/Bahia), informa a assunção do cargo de Promotor Público do Dr. Abdon Baptista;

- Em 28 de Outubro de 1880, o Jornal O Monitor (Salvador/Bahia), informa o pedido de exoneração do cargo de Promotor Público do Dr. Abdon Baptista.

Estes elementos por si, desconstroem o argumento de que ele teria adentrado o território catarinense em 1870, já que este achava-se mais ocupado com outras questões e trabalho que o colocam em um contexto diferente daquilo que se evidencia No entanto, a autora Raquel S. Thiago (1988) aponta para o fato de este ter chegado à região por volta de 1880 , período em que teria se exonerado do cargo de Promotor Público, ano de seu casamento, isto é, « Abdon vindo da Bahia, à São Francisco do Sul de onde se dirige a Joinville no ano de 1880 e casando-se com D. Thereza Nóbrega de Oliveira , filha do Coronel José Antônio de Oliveira,» sem tratar de pormenores , no que diz respeito ao que levou este a fixar-se na região e mesmos os elementos que cercaram o enlace. Elemento que denota o cunhadismo como uma interessante forma de ascensão social, bem como para acessar certas esferas de poder e de relações, servindo entre outras questões como forma de ascensão e encaixe social, colocando por terra barreiras de cor, que poderiam conjugar-se contra Abdon.

Neste contexto de relações sociais de Abdon observa-se o fenômeno do Coronelismo e em particular o Coronelismo Urbano. Ao analisar a obra de Raquel S.Thiago (1988) esta destaca o caráter relativo deste coronelismo, no sentido do coronel não ser necessariamente um grande latifundiário ou membro da Guarda Nacional, no que estabelece uma associação entre o status de médico (Doutor) ao de coronel. As práticas adotadas pelos coronéis em relação ao eleitorado, não eram muito diferenciadas das praticadas em outras regiões do Brasil, na medida em que estes se utilizavam de estratégias comuns como o voto de bico-de-pena, bem como da promoção de festejos, distribuição de alimentos, entre outros aspectos com objetivo de "cativar" o eleitor, no que autora salienta um episódio anedótico, onde os eleitores afirmam votar em Abdon, não apenas por que ele lhes serviu um bom churrasco, já que os outros também o faziam, entretanto segundo estes «um bom churrasco deve ter uma garrafa de cerveja» e por este motivo é que votavam em Abdon, 
elemento este que aponta para a habilidade política deste, e que evidencia a sua perspicácia, frente aos demais.

Contudo, esta habilidade e capacidade sofrem críticas ao grupo representado por Abdon, o dos coronéis que é visto como sem ideologia, mas dotado de desejo de poder, que, entretanto, é muitas vezes suplantado pelo interesse na coisa pública, que acaba por se materializar em forma de ação política concreta, que se evidencia nas obras públicas por ele erigidas. De modo que muito do desenvolvimento econômico e social de Santa Catarina daquele momento em parte é atribuída a Abdon e a oligarquia do mate.

Ainda por volta de 1880, entre a sua chegada e o seu casamento, Abdon filia-se a um projeto e ao partido político (Partido Liberal) ao qual seu sogro se achava ligado. Uma das primeiras práticas adotadas por Abdon e seu sogro é a aquisição e a edição de um jornal como forma de lançar-se politicamente do qual posteriormente seria um dos seus principais redatores. Nesta disputa o Partido Conservador se utilizava do Jornal "A União" para lançar críticas em relação a Abdon que neste é retratado sob a alcunha de Dr Penúria - talvez algum tipo de lembrete que buscava apontar para sua origem ou lugar social, bem como sua ascendência negra, Thiago (1988, p.49) cita uma passagem do jornal, onde lê-se , «(...) Os serviços reais, o grande mérito, o talento, a virtude, a ilustração, tudo ali é abatido, espezinhado pela negra, maldita e vil paixão (...)»

Neste contexto de rivalidade, Abdon não consegue eleger-se devido ao fato de que por volta de 1883, ainda ser um tanto desconhecido na região, entretanto, apresenta-se como um forte oponente na disputa que se travou, fato que lhe rendeu um grande rival Alfredo D'Escragnolle Taunay, que militava no Partido Conservador e flertava com propostas liberais como o abolicionismo e a proteção ao direito dos estrangeiros. Abdon percebe a importância estratégica de bater - ser contra Taunay, fato que o leva a editar parte de seu jornal em alemão e lançando críticas contra o mesmo, apontando que as suas ideias não se coadunavam com as do partido, procurando expô-lo.

Nestas circunstâncias, está sendo votada a lei do Sexagenário que encontra opositores em ambas as frentes, devido ao teor desta que liberava os escravos que não tinham condições de manter-se, livrando os proprietários do ônus de cuidá-los, fato que leva Abdon a lançar várias críticas a Taunay por este não ter tomado posição frente ao tema. Na tentativa de desmobilizar Abdon, Taunay tenta provar que este não era formado em Medicina, entretanto, a estratégia provou - se fraca pois o mesmo era formado e já contava com o exercício da profissão no local a 4 anos, de 
modo que este adverte seus partidários que qualquer crítica neste sentido seria desvantajosa para o grupo, mesmo assim, críticas em relação a Abdon continuam.

Na década de 80 do século XIX, Abdon por sua vez elege - se deputado em 1884 e Presidente da Câmara de São Francisco do Sul em 1887. Por volta dos anos de 1884, os ventos da política estão mudando e enuncia-se no horizonte uma mudança no modelo político com o movimento republicano, associado ao movimento abolicionista. Dentro destes movimentos que hora se operam na sociedade, ocorrem debates sobre a libertação dos escravos que coloca dois modelos antagônicos, onde destaca-se o campo representando os que queriam a conservação do modelo rural e escravista existente e a cidade com o projeto modernizador que via com interesse a libertação dos escravos.

O Brasil deste momento começa a identificar-se como um tipo de sociedade que se espelha no modelo europeu de modernidade, que se quer urbano, neste cenário, ganha força a propaganda republicana, gerando dissidência entre os liberais ainda em 1887. Abdon se vê no limiar da mudança balançando frente aos ideais republicanos, embora, resista por conta de sua posição política e os compromissos advindos desta. Assim, quando a mudança do modelo político finalmente se efetiva Abdon muda com ele aderindo ao republicanismo.

As mudanças decorrentes da nova situação política vivenciada pelo país, com a deposição das autoridades locais, a mudança nos governos dos Estados e a nova centralidade de elementos até então periféricos como era o caso dos Republicanos, farão com que as antigas elites revejam as suas posições no sentido de manterem - se no poder. A mudança política, afetou Abdon no momento que este estava no exercício do poder como Vice-presidência da Província. Esta nova condição fez com que Abdon e muitos outros mudassem com vista a tornarem-se mais aderentes a nova situação. Apontando que a questão ideológica acabou por se configurar apenas, como algo circunstancial em torno da questão do poder.

No novo cenário de disputas eleitorais a reorganização das forças políticas gerou alianças distintas, a aliança organizada pelos liberais sai derrotada frente a aliança oficial. Surgindo desta o Partido da União Federalista, montado pelos liberais. Mas, nas novas eleições os Republicanos impuseram nova derrota aos liberais, em todos os lugares que disputaram, menos em São Francisco do Sul, onde a liderança efetiva de Abdon, fez - se sentir. Contudo, há uma nova mudança no cenário político advindo das tomadas de decisões e posterior renúncia de Deodoro, o que fará com 
que haja um novo realinhamento do poder. Este fato dará ocasião para uma movimentação dos federalistas para retornarem ao poder.

Neste contexto de mudanças políticas, Abdon retorna ao poder sendo empossado na Intendência de Joinville, o que denota sua importância na região, por outro lado, observa - se uma mudança bastante complicada no círculo do poder, onde os Republicanos mais uma vez são postos de lado e os federalistas se consolidam no poder. No que Abdon encontra uma estrutura favorável para sua consolidação no poder e assunção do cargo de Prefeito de Joinville bem como, de deputado de Santa Catarina ao mesmo tempo.

Eclode a revolução com os federalistas tomando Rio Grande do Sul, em um primeiro momento as forças de Santa Catarina resistem, no entanto, devido a incapacidade de resistir rompem com o governo central. Abdon a princípio toma uma posição quase neutra do ponto de vista político aderindo posteriormente aos federalistas. Os revoltosos desembarcam em São Francisco do Sul, dirigem-se a Joinville. Abdon manobra a situação para evitar violência na cidade enquanto observa a entrada de tropas legalistas.

As tropas legalistas descem do Paraná a fim de driblar os revoltosos. Os revoltosos por sua vez tentam recrutar à força membros entre a população que resiste, sendo que estes acabam barrados pela população que prefere manter-se neutra durante o episódio, enquanto estas requisitavam a força cavalos e armas da população. Em meio ao conflito Abdon é aconselhado pelo capitão Von Altrock a organizar as requisições para as tropas por meio da Câmara a fim de evitar os conflitos entre as tropas e a população. É ainda acautelado por Friedrich a zelar pela neutralidade com o intuito de que estas tropas retirassem o mais breve possível. As tropas Federalistas deixam Joinville, obtém várias vitórias no Paraná, mas enfrentam retração com várias derrotas frente às tropas legalistas, seguidas do fim da Revolução e queda dos federalistas, fato que leva a troca de poder e a queda de Abdon Baptista e seus conselheiros.

A troca de poder se sucedeu no nível estadual e culminou com a prisão e execução de simpatizantes e militares federalistas, o que levou Abdon a refugiar-se na Argentina. Em 1895 é concedida a anistia aos Federalistas, o que possibilita o retorno de Abdon para Joinville e ao poder, mas, não sem resistência, desta vez dos teuto-brasileiros que se batiam-se contra o poder lusobrasileiro representado por Abdon.

Neste contexto o Kolonie - Zeitung critica não só o poder luso-brasileiro representado por Abdon, mas a rede nepote na qual este se acha circunscrito de tal modo que, este junto da família 
Oliveira dominava quatro distritos e o Norte Catarinense fato que alijava os teutos do poder. As críticas fizeram sentir-se, fazendo com que Abdon perdesse a eleição de 1898 por pequena margem de votos 619 a 711 para Gustavo Richlin. Apesar da derrota, Abdon se achava pouco abalado, pois este possuía grande apoio do Grupo do Mate.

Abdon retorna ao poder no cargo de deputado em 1903 como resultado da fusão partidária onde Republicanos e Federalistas, onde estes tiveram que superar as suas divergências em nome de um projeto de poder. Após optar pela coalizão, chega ao cargo de Deputado em 1903, e em seu discurso apoia um fortalecimento do exército como meio de fortalecer o Estado Nacional, no entanto entra em desacordo com colega de mesmo partido que pretende fortalecer o exército como forma de controle sobre europeus e seus descendentes radicados no Brasil, sendo por isto vítima de críticas e definido como "Germanófilo", do que Abdon se esquivava apontando para a importância do trabalho desta população para o progresso do Brasil, apontando que entre estes possui tanto admiradores quanto inimigos.

Abdon não vê interesse em tornar o país uma nação beligerante como forma de dominar o território assim como de afirmação nacional, entretanto, via sim a necessidade desta materializar-se no crescimento populacional e na ocupação do território esta possibilidade, e com extrema habilidade procurou harmonizar o seu discurso ao do opositor conduzindo ambos ao interesse nacional. Neste momento coloca-se na disputa ao cargo de Vice-Governador de Santa Catarina. No que os jornais se confrontam acerca da vantagem de tê-lo ou não no cargo, por outro lado, disputas e críticas acerca de Abdon, e oportunamente cessam quando da sua eleição para o cargo, sendo alvo de elogios de antigos desafetos políticos, fato que reforça a liderança e o poder político deste na região.

Assume cargo de deputado federal em 1911, neste período trabalha no sentido de buscar auxílio econômico à Santa Catarina que se acha em estado de calamidade devido às chuvas. Evidencia-se a eficácia das ações de Abdon que se efetivam por meio de decreto lei aprovado proposto por este onde concede - se o crédito necessário à reconstrução do Estado

Abdon assume a cadeira de Senador em 1913, busca apaziguar o parlamento que pretende pedir moratória por conta da baixa nas exportações decorrentes da I Guerra, e que haviam prejudicado as exportações do país, no entanto Abdon busca tranquilizar a todos, afirmando que a situação é temporária. No entanto era a favor de uma moratória externa com intuito de proteger os 
comércios e produtores nacionais dos juros praticados pelo mercado, internacional por conta da Guerra.

Em 1918, Abdon assume os cargos de deputado e prefeito de Joinville, dedicando mais ao primeiro deixando o segundo á cargo de seus substitutos, é convocado por membros do partido a candidatar - se ao cargo de governador, entretanto, devido a um certo desinteresse, bem como ao desejo de evitar novas disputas com a nova elite que despontava no horizonte, este preferiu afastar se, abrindo caminho para esta.

Este novo grupo por sua vez se consolidará no Estado de Santa Catarina, "desmontando" o grupo político de Abdon no Estado. Buscam ainda avançar sobre Joinville, território político de Abdon, no entanto este falece, em 1922, abrindo caminho de forma natural para e entrada deste novo grupo no Estado. O sucessor político de Abdon Baptista na política catarinense, de Joinville, será Carlos Gomes de Oliveira, advogado e Senador da República na década de 1950.

\section{CONSIDERAÇÕES FINAIS}

Discorrer sobre a trajetória de Abdon Baptista, é desvencilhar um conjunto de fatores imbricados, sobrepostos e justapostos, um homem moderno que move-se em meio a este processo de construção e reconstrução em um país que se quer fazer moderno, em um contexto nacional altamente contraditório.

Por outro lado, é como observar um processo físico, onde os vários objetos caminham e movimentam-se ao mesmo tempo, de forma quase conjugada e ao mesmo tempo caótica, em um processo de desterritorialização deste sujeito, uma vez, que a sociedade passa por um grande conjunto de transformações onde a ideia de Estado Nacional está em processo, a escravidão está chegando ao seu fim - ainda que do ponto de vista institucional - a monarquia vislumbra seu crepúsculo, a sociedade rural, mesmo que lentamente, converte-se em uma sociedade urbana, novas fronteiras abre-se, o novo está surgindo...

Entretanto, carregando consigo as vicissitudes de um sistema arcaico que vai se ressignificando, se readaptando, trazendo consigo, ainda que de forma indelével o patriarcalismo, 
patrimonialismo, o familismo amoral e mesmo uma estrutura social de classes extremamente durável, como aponta Florestan Fernandes (1976) ao ocupar-se da questão do negro para explicar a nossa sociedade e mesmo para explicá-la a partir do drama do deste, que se faz presente através da inclusão deste na nascente sociedade de classes que hora se agiganta, sem que contudo, ele seja inteiramente absorvido nesta dinâmica.

\begin{abstract}
O verdadeiro dilema do processo de transição para a modernidade no Brasil é que, para Florestan, nossa sociedade nunca chegou a se constituir, efetivamente, como uma sociedade de classes. Isto é, a ordem social competitiva enfrentou obstáculos quase intransponíveis. No caso da pesquisa, ela revelou que o "negro" encontrou pela frente toda sorte de dificuldades em seu processo de ascensão social. Entre tais dificuldades, talvez a principal fosse o preconceito racial, que se traduzia em resistências abertas ou dissimuladas para sua admissão em pé de igualdade com os brancos. Em outras palavras, o preconceito de cor e a discriminação racial atuaram como elementos impeditivos, verdadeiros obstáculos à formação de uma sociedade de classes. Na verdade, tais manifestações eram indicadores de padrões socioculturais tradicionalistas, conservadores, muitas vezes opostos à racionalidade capitalista. Contudo, atuavam como mecanismos sutis de reprodução de desigualdades em meio ao processo de modernização. (TRINDADE,2014 p.115)
\end{abstract}

Grosso modo, a figura de Abdon insere-se nesta lógica, na medida em que tem que dialogar com estas mesmas estruturas tradicionais que compõe a lógica vigente no Brasil de então. Mesmo em produções mais recentes como "Na Teia do Nepotismo" de Ricardo de Oliveira (2012), que demonstra a ascensão e a predominância de das elites e estruturas tradicionais através de relações como compadrio, mandonismo, o coronelismo entre outras relações hierárquicas, que acabam por evidenciar os ditos "padrões socioculturais tradicionalistas, conservadores, muitas vezes opostos à racionalidade capitalista" apontadas por Florestan, bem como outros autores, que se colocam como obstáculos sociais a ascensão do negro no Brasil.

Assim, a questão do negro na sociedade brasileira, tomando como exemplo a figura de Abdon Baptista torna-se um problema quase epistêmico, pois se encontra ligado a uma forma de ver o mundo, ou mesmo de percebê-lo que se acha permeada por várias questões, entre elas a permanência de certos padrões sociais, e a ideia da construção de uma sociedade moderna que se quer também branca, e o faz a partir de um certo padrão de normalidade, se insere dentro daquilo que se compreende como branquidade normativa, sendo a:

(...) branquidade normativa, ou seja, o conjunto de ideias que apresenta a condição de indivíduo de cor branca como um parâmetro de normalidade, frente aos demais, que por não participarem da mesma condição não o são. "Dentre as formas latentes de discriminação contra o não branco, talvez seja a negação de seu direito à existência humana - ao ser - a mais constante: é o branco o representante da espécie. Por esta sua condição, 
seus atributos são tidos como universais. A branquidade é a condição normal e neutra da humanidade: os não brancos constituem exceção. ${ }^{11 “ ~(B A R B O S A, ~} 2013$ p.4)

Elemento que funciona como uma espécie de tapume que impede os indivíduos, incluindose aí os próprios negros de ver-se como um agente social e histórico capaz de realizar transformações notáveis frente a sociedade, elemento que denota a invisibilidade social e histórica dos negros no Brasil.

Cria-se uma espécie de obstrução perceptiva que impede a identificação destes sujeitos com algo mais do que força física (trabalhador braçal) e menos como um ser sensível dotado de capacidade e sensibilidade intelectual (médico, engenheiro, advogado, etc.), sobretudo dotados de condições de intervir na sociedade, fato e/ou problema que reflete o drama do negro ao longo da História da sociedade brasileira , que ao negar a sua existência como agente histórico, acaba por negar-lhe o seu passado, elemento que lhe furta o presente.

O que se procurou neste artigo não foi aprofundar questões de ordem epistêmica, mas, evidenciar certos aspectos subjacentes que parecem estar presentes na sociedade e em sua história e que portanto, apontam para elementos importantes, no que diz respeito a participação do negro na sociedade brasileira, e que se fazem presente na figura de Abdon Baptista. Fatos estes que por si só denotam a importância da discussão sobre a filiação e pertencimento racial e social de Abdon.

Neste sentido parece importante refletir acerca do título, no mínimo peculiar desta pesquisa e que teve como referência a obra de Charles Dickens intitulada "Um Conto de Duas Cidades", que de maneira resumida, conta a história de um sujeito que muda de seu país, de nome e abandona a si mesmo e seu passado para reconstruir-se como um outro sujeito, em um lugar distante reinventando-se, deixando para traz a carga de seu passado, que para si é um estigma herdado fruto das muitas desonras de sua família, o qual, guardada as devidas proporções, também é o que sucede ao Abdon, que busca ao longo de sua vida deixar o passado para traz, não que o faça deliberadamente, mas, o faz como estratégia de sobrevivência que tem no branqueamento sua chave de fuga desta condição. O processo de branqueamento, tal e qual é apresentado, apresenta-se carregado de alto grau de negatividade, na mediada em que se coloca como única alternativa em uma sociedade fechada.

\footnotetext{
${ }^{11}$ ROSEMBERG, Fulvia (1985). Literatura infantil e ideologia. SP: Global.
} 
Abdon Baptista, um intelectual negro, e que pode ser alçado a este patamar, devido a sua formação como Médico, bem como, pelos discursos proferidos durante sua carreira política, que evidenciam sua capacidade de articular-se intelectualmente frente as adversidades e disputas advindas destes dois campos. Quanto ás questões que implicam no intuito de demonstrar a sua produção intelectual, estes elementos se fazem presentes em vários momentos quando vê-se a necessidade de Abdon firmar-se nas disputas políticas, seja quando é questionado quanto a sua capacidade como médico, seja quando defende a necessidade de unidade nacional durante o período marcado pela Primeira Guerra e mesmo da importância que dá ao processo educativo, quando do episódio da reforma educacional promovida por este no Estado de Santa Catarina, e que em grande medida é também uma atitude de forte caráter intelectual, tendo que justificar-se racionalmente ante aos diferentes grupos de interesse e esferas de poder na qual circulava.

Dado que, grande parte da capacidade de Abdon de circular dentro deste sistema dá-se pelas sucessivas demonstrações de aptidão intelectual, elemento este profundamente ligado a sua integração a classe dominante tradicional, da região de Santa Catarina. Outra evidência dá-se por conta de Garcia (2011), que em sua comunicação de pesquisa intitulada "Intelectuais Negros no Pós Abolição: associativismo negro em Florianópolis (1915 - 1925)”, destaca o nome de Abdon, entre outros nomes de intelectuais negros, onde lê-se:

Em Santa Catarina não se pode menosprezar as trajetórias de Abdon Batista, Cruz e Souza, Manoel Ferreira de Miranda, Antonieta de Barros, Leonor de Barros, Ildefonso Juvenal, Trajano Margarida, João Rosa Júnior dentre tantos outros. Diante das evidências podemos levantar a hipótese que houve, nesta época, um grupo intelectual negro em Santa Catarina e no Brasil. (GARCIA, 2011 p.04)

É o mulato, o intelectual mulato, no qual Gilberto Freyre (2003) pensava na obra "Sobrados e Mucambos" do qual Renato Silva (2010) acentua, apontando que

O mulato seria a reapresentação de um desses espaços que era considerado ambíguo e marginal. Mas o mulato também foi segundo escritor pernambucano, uma força nova e triunfante dessa nova geografia: o espaço urbano. $\mathrm{O}$ bacharel mulato seria o primeiro ator do espaço público em formação. Ser híbrido, "meio-homem", "meia raça", o bacharel mulato transferiu involuntariamente essas qualificações para espaço público brasileiro. (SILVA,2010 p.6-7)

Desta feita, ao referir-se a Abdon este é hora representado como negro, hora como mulato, em fim qual seria a pertença racial desta tão notória personagem? Vale lembrar que de modo geral e 
como aponta o próprio Oraci Nogueira, que esta questão não se trata de uma tarefa fácil solução, uma vez que:

\begin{abstract}
No campo das relações inter-raciais, como já foi visto, a regra é o branco evitar a susceptibilização do homem de cor. A própria palavra "negro", geralmente, se reserva para os momentos de conflito, preferindo-se, nas fases de acomodação, expressões como "pardo", "mulato" e "preto", quando não eufemismos como "moreno", "caboclo" (em relação a indivíduos negroides) etc. Mesmo quando ocorrem situações em que a presença do indivíduo de cor seria considerada indesejável ou incômoda, o mais comum é se lhe "dar a entender" o problema que está pendendo ou que ele "está causando", sem se chegar "ao extremo" de lhe chamar franca e abertamente a atenção. Uma das consequências diretas da orientação aqui assinalada é o caráter intermitente que tende a assumir a consciência de raça, no brasileiro de cor. Outra consequência, não menos importante, é que o processo de acomodação é facilitado pelo "desarmamento afetivo" do negro. (NOGUEIRA, 2006, $\mathrm{p}, 305)$
\end{abstract}

$\mathrm{O}$ artigo pretendeu ao debruçar-se sobre as questões relativas a biografia de Abdon, em um primeiro momento, a busca deu-se pela trajetória do Abdon criança, e da sua reconstrução a partir do lugar ou lugares ignorados e diversos de onde se pudesse localizar qualquer indício sobre a sua trajetória, seja ele a Vera Cruz de Itaparica, seja ele o documento, seja ele o contextual.

Num segundo momento, surge a filiação e a formação de um ethos profissional, que não resume-se à si mesmo, que transborda para outras dimensões, sendo a principal delas a política e o desejo de mando, que vão se moldando e se desenvolvendo durante este processo. A busca da fronteira do lugar onde este sujeito pode explicitar-se, o ser fronteiriço, em meio a fronteira do lugar que está por se construir, em uma dimensão quase dialética onde o "operário faz a coisa e a coisa faz o operário ${ }^{12 ", ~ n o ~ q u a l ~ o ~ M e ́ d i c o, ~ D o u t o r, ~ o ~ C o r o n e l ~ e ~ o ~ E m p r e s a ́ r i o ~ s e ~ c o n s t r o e m ~ e ~ m i s t u r a m-s e . ~}$

Abdon se forja político e intelectual dotado daquelas capacidades que Maquiavel (2004) observava, no bom político que conseguia conjugar a virtù, a fortuna e a ocasião, em situações que tiveram resultados desastrosos para muitos como a Revolução Federalista, ocasião onde teve que retirar-se, para não morrer e mesmo assim, ao retornar conseguiu estabelecer-se de onde parou, apesar de sua situação.

Contudo, Abdon do início ao fim não foi self-made-man, mas foi o resultado de uma cadeia de relações, de capitais sociais e familiares, hora mais evidentes, no caso de seu casamento, hora menos evidentes, como as circunstâncias de seu nascimento até a Faculdade de Medicina da Bahia.

12 MORAES, Vinícius de. O operário em construção. In: Nova Antologia Poética. São Paulo, Companhia das Letras, 2005 
As relações referentes as estruturas de poder, a formação cultural, as trajetórias familiares, e toda uma conjuntura relativa a uma correlação de forças sociais, culturais entre outras, que atuaram sobre, em torno, assim como na sua vida e a partir do próprio indivíduo, farão com que este venha a emergir como esta figura marcante no nordeste catarinense e mesmo no que toca seu papel frente a realidade e a trajetória deste importante intelectual e político negro brasileiro.

Fatos e elementos estes que se dão em um universo em que o antigo senhor colonial se metamorfoseará em homem de negócios, abrindo mão de certos privilégios inerentes ao sistema de outrora, mas, não do lugar social constituído, abrindo dentro de certos limites espaço para as modernizações no mundo do trabalho e a libertação dos escravos, fenômeno que se acha presente no ápice da crise do sistema escravocrata, porém, esta liberdade, bem como, as mudanças ocorridas no mundo do trabalho e econômicas estarão eivados pelo viés conservador que produziu a sociedade escravista colonial. Fenômeno este que se constitui naquilo que Florestan Fernandes (1976) denominou como um circuito fechado, no qual a ascensão de Abdon acabou por se constituir, guardadas as devidas proporções, em um processo de "tunelamento social ${ }^{13 "}$ por assim dizer, no que foge ao destino sombrio reservado ao negro e sob certos aspectos, antevistos por Joaquim Nabuco, rompendo assim através deste "tunelamento" o circuito fechado enunciado por Fernandes.

Assim o que se verá, será a manutenção de determinadas ordens, do ponto de vista do lugar social, político e econômico de estruturas anteriores sob novos termos, dos quais Abdon parece hora servir-se, hora sacudir-se no intuito de melhor assentar-se, mesmo colocar-se frente aos obstáculos enfrentados.

Deste modo, seria quase uma leviandade tentar resumir a capacidade de Abdon apenas a sua capacidade política, já que mesmo como foi demonstrado ao longo destas considerações, que para a análise de sua trajetória de vida, foram necessário utilizar-se de um repertório conceitual bastante amplo, do qual a trajetória é um dos elementos, que passam pelos diversos campos do conhecimento tendo como norte a Sociologia, bem como a Sociologia Política, a História, o

\footnotetext{
13 Tunelamento Quântico é um efeito *quântico* que permite a uma partícula (melhor dizendo: a qualquer objeto quântico) atravessar regiões que são proibidas classicamente. Ou seja, ele "permite" (aonde "permite" quer dizer "existe uma probabilidade não nula") que este atravesse "barreiras de potencial" que, em mecânica clássica, não poderia atravessar. Fonte: FERRANTE, Daniel Doro. O que é efeito Tunelamento? : Queremos Saber Física UFC, Site Serara $\begin{array}{llll}\text { da Ciência[Internet],.Acesso: } & \text { em } & \text { 20/02/2015. } & \text { Disponível }\end{array}$ em:http://www.searadaciencia.ufc.br/queremosaber/fisica/oldfisica/respostas/qr0402.htm

O empréstimo deste termo tem por objetivo estabelecer uma analogia entre as forças sociais que tendem a conservação das posições sociais impostas aos indivíduos e forças iguais e contrárias que possuem a probabilidade de romper determinadas tendências relativas as forças observadas na vida social, como as que permitiram a Abdon, romper com o status de homem negro (escravizado), para o de médico, político e empresário bem sucedido.
} 
Interacionismo Simbólico, isto apenas para explicitar alguns recursos conceituais analíticos aqui empregados. Neste caso o emprego de um cabedal tão amplo de teorias se fez necessária devido à complexidade do tema, parece lógico afirmar que foi um esforço de dar conta de uma totalidade, que de fato é tarefa impossível, de tal modo que a pesquisa acabou por "abrir mais portas do que as que fechou".

\section{REFERÊNCIAS}

BARBOSA, Marco Aurélio (2013). Invisibilização Social do Negro na História de Curitiba: Uma Abordagem Centrada nos Currículos De Educação Básica. $21^{\circ}$ EVINCI.

BOURDIEU, Pierre (2006). A ilusão biográfica. In: FERREIRA, Marieta de Moraes e AMADO, Janaina. (org.). Usos \& abusos da história oral. 8.ed. Rio de Janeiro: FGV. pp.183-191.

CASTELLUCCI JUNIOR, Wellington (2005). Pescadores e Roceiros: Escravos e Forros na Ilha de Itaparica entre os anos 1860-1888. XXIII Simpósio Nacional de História: Guerra e Paz, Londrina, v. 01, p. 01-08.

CASTELLUCCI JUNIOR, Wellington (2010). Tramas, terra e liberdade: família escrava e alforrias na Ilha de Itaparica no século XIX. Afro-Ásia, n. 42, p. 63-107,

CORADINI, Odaci Luiz (1997) Grandes Famílias e Elite "Profissional" na Medicina no Brasil. História, Ciências, Saúde, v. 3, n. 3.

FERNANDES, Florestan (1976). Circuito Fechado. São Paulo: Hucitec,

FREYRE, Gilberto.( 1981). Casa Grande e Senzala. 21 ed. Rio de Janeiro: José Olympio

GARCIA, Fábio (2011). Intelectuais negros no pós-Abolição: associativismo negro em Florianópolis (1915-1925).Anais Eletrônicos ANPUH. Fortaleza.

GOFFMAN, Erving (1988). Estigma: notas sobre a manipulação da identidade deteriorada. $4^{\mathrm{a}}$ ed. Rio de Janeiro: Zahar.

LEITE, Ilka B (1996). Negros no sul do Brasil - invisibilidade e territorialidade. Santa Catarina: Letras Contemporâneas.

MAFRA, Antônio Dias; CARDOSO, Maria Angélica; HOFF, Sandino (2007). A educação escolar de Santa Catarina no período do ciclo da erva-mate. Roteiro, v. 32, n. 1, p. 95-122. Disponível em: <http://editora.unoesc.edu.br/index.php/roteiro/article/viewFile/340/88> Acesso em: 28/11/14. 
MAQUIAVEL, Nicolau (2004) . O PRÍNCIPE . São Paulo, Martins Fontes.

MOCELIN, Daniel Gustavo (2010). História e trajetória de vida: Fato Sociológico blog (internet). Porto Alegre,RS. jun. 2010. Disponível em: <http://fatosociologico.blogspot.com.br/2010/07/historia-e-trajetoria-de-vida.html>. Acesso em: 05 mar. 2014.

NOGUEIRA, Oracy (2006). Preconceito racial de marca e preconceito racial de origem: sugestão de um quadro de referência para a interpretação do material sobre relações raciais no Brasil. Tempo social, v. 19, n. 1, p. 287-308,

OLIVEIRA, R. C.(2012). Na Teia do Nepotismo. Sociologia Política das Relações de Parentesco e Poder Político no Brasil. 1. ed. Curitiba: Insight,

SILVA, Renato da (2010). O "mulato" e "homem cordial”: as raízes do espaço público no Brasil. Revista Magistro, v. 2, n. 1.

THIAGO, Raquel S (1988). Coronelismo Urbano em Joinville: o caso de Abdon Baptista. Florianópolis: Governo do Estado de Santa Catarina.

WEBER, Max; GERTH, Hans Heinrich; MILLS, Charles Wright (2002) Ensaios de sociologia. $5^{\circ}$ ed. Rio de Janeiro: LTC..

\section{A STORY OF TWO CITIES: PATH AND ABDON LIFE BAPTIST}

\footnotetext{
Abstract

This work intends to deal with the life path of Abdon Baptista, who was doctor, journalist and politician, born in Bahia in 1852, becoming notorious figure in Joinville, Santa Catarina. Its history is complex and combines a lush set of stratagems, which led to its political and social climbing, descendant of former slaves the Mayor of Joinville, Senator and Deputy Governor of Santa Catarina in 1905. By reconstructing the trajectory to rise this remarkable figure, we see how it reinvents itself, builds social capital to become a doctor, it is stated through the new frontier of northern Santa
} 
Catarina, enters the power relations web of this universe, through incorporation into a family of traditional oligarchy local and even is founded as an important personality in the time of transition in which appear several major events for Brazil and the world, between the years 1880 until 1922, date of his death.

Key-words: Abdon Baptista. Sociability networks. Black. Path of Life. Policy and to power. 